\section{Estimating the volleyball team ranking in the 2016 Rio Olympics by artificial neural network and linear model}

\begin{abstract}
This study was conducted to estimate the Olympic ranking of the games played in the qualifying groups by the countries that were qualified for the 2016 Rio Olympics in volleyball branch by analyzing with the developed artificial neural networks (ANN) and linear equation model. In the study, the difficulty level of all games $(n=324)$ that total 22 teams played in the qualifying for the 2016 Rio Olympics in volleyball branch (11 female and 11 male volleyball teams) and International Volleyball Federation (FIVB) ranking score was evaluated separately. Feedforward network structure having two hidden layers in the modeling with ASS developed for 9 different input variables was preferred in the study. In addition, linear modeling method, which provides an easier calculation than artificial neural networks, was performed by "regress" instruction in MATLAB. In the female group, the percentage
\end{abstract}

\section{Özet}

Bu çalışma 2016 Rio Olimpiyatlarına voleybol branşından katılma hakkı kazanan ülkelerin eleme gruplarındaki maçlarının, geliştirilen yapay sinir ağları (YSA) ve doğrusal eşitlik modeli ile analiz edilerek olimpiyat siralamasinın tahmin edilmesi amac1 ile yapılmıştur. Çalışmada 2016 Rio Olimpiyatlarına voleybol branşından katılan (11 kadın ve 11 erkek voleybol takımi) toplam 22 takımın grup elemelerinde oynadığ1 tüm maçlar $(n=324)$ zorluk derecesi ve Uluslararas1 Voleybol Federasyonu (FIVB) siralama puanı göz önüne alınarak değerlendirilmiştir. Çalışmada dokuz farklı giriş değişkenine göre geliştirilen YSA modeli ile modellemede iki gizli katmana sahip ileri yayılımlı ağ yapisı tercih edilmiştir. Ayrıca çalışmada YSA'na göre çok daha basit bir hesaplama sağlayan doğrusal modelleme yöntemi de, MATLAB'de bulunan "regress" komutu ile gerçekleştirilmiştir. Kadınlar grubunda; test verilerine bakıldığında modellerin

\footnotetext{
1 Doç. Dr. Gazi Üniversitesi, Spor Bilimleri Fakültesi, Antrenörlük Eğitimi Bölümü, c akarcesme@hotmail.com (iD) Orcid ID: 0000-0001-6231-0950

2 Dr. Öğr. Üyesi Niğde Ömer Halisdemir Üniversitesi, Spor Bilimleri Fakültesi, Antrenörlük Eğitimi Bölümü, hasanaka06@gmail.com (iD) Orcid ID: 0000-0003-0603-9478

${ }^{3}$ Dr. Öğr. Üyesi, Milli Savunma Üniversitesi, sozden@kho.edu.tr (iD) Orcid ID: 0000-0002-1309-9391

4 Doç. Dr. Niğde Ömer Halisdemir Üniversitesi, Spor Bilimleri Fakültesi, Beden Eğitimi ve Spor Bölümü, zaitburak@gmail.com (iD) Orcid ID: 0000-0002-5102-4331
} 
Akarçeşme, C., Aka, H., Özden, S., \& Aktuğ, Z. B. (2020). Yapay sinir ağları ve doğrusal model ile 2016 Rio Olimpiyatlarındaki voleybol takım sıralamasının tahmin edilmesi. Journal of Human Sciences, 17(4), 1069-1078. doi:10.14687/jhs.v17i4.6077

mean error value of the models was calculated as 18.86 by ANN model, and as 4.53 by linear model. In male groups, it was calculated as 19,34 by ANN model, and as 0,74 by linear model. According to the modeling results obtained in the study, both female and male volleyball teams' results were modeled with a higher accuracy by linear model. As a result, team rankings of the volleyball branch in the women's group in the 2016 Rio Olympic Games was estimated with an accuracy over 98\% separately by ANN modeling regression results and linear modeling regression results. In men's volleyball games, it was estimated with an accuracy over $98 \%$ by ANN modeling regression results, and with an accuracy over $99 \%$ by linear modeling regression results. It can be stated that the difficulty level of the games that countries participating in Olympics in volleyball branch played in the qualifying groups and FIVB ranking scores are among the variables that have a significant effect on determining the Olympic ranking.

Keywords: Volleyball, artificial neural network, linear modeling, competition analysis.

(Extended English summary is at the end of this document) yüzde ortalama hata değeri, YSA modelinde 18.86, doğrusal modelde 4.53 olarak; erkekler grubunda ise YSA modelinde 19.34, doğrusal modelde 0.74 olarak hesaplanmışur. Çalışmada elde edilen modelleme sonuçlarına göre; hem kadın hem de erkek voleybol takımlarının sonuçları doğrusal model ile daha yüksek doğrulukla modellenmiştir. Sonuç olarak, kadinlar kategorisinde 2016 Rio Olimpiyat Oyunlarında voleybol branşının takım sıralaması, YSA modelleme regresyon sonuçları ve doğrusal modelleme regresyon sonuçları ile ayr1 ayrı \%98'in üstünde doğrulukla tahmin edilmiștir. Erkek voleybol maçlarında ise YSA modelleme regresyon sonuçları \%98'in üstünde, doğrusal modelleme regresyon sonuçlar1 ise \%99'un üstünde doğrulukla tahmin edilmiştir. Voleybolda Olimpiyatlara katılan ülkelerin eleme gruplarında oynadıkları maçların zorluk derecesi ve FIVB siralama puanlarının Olimpiyat sıralamasının belirlenmesine önemli etkisi olan değişkenlerden olduğu söylenebilir.

Anahtar Kelimeler: Voleybol, yapay sinir ağları, doğrusal modelleme, müsabaka analizi.

\section{Giriş}

Voleybol farklı şiddet düzeylerinde aktivitelerin olduğu, sporcuların fiziksel ve kondisyonel özelliklerinin çok yönlü gelişimini gerektiren bir takım sporudur (Gabbett ve Georgieff, 2007; Gabbett ve Georgieff, 2004; Marques ve ark., 2009). Üst düzey sporcularda çok yönlü gelişim sağlanabilmesi için aralarında teknolojinin de bulunduğu farklı alanlardan faydalanmak gerekmektedir. Son yıllarda bilgisayar teknolojilerinin kullanımının yaygınlaşmasıyla antrenörler sporcuların ve takımların performans analizlerini kolaylıkla yapabilmektedir. Üst düzey voleybolda müsabaka analiz programları, analiz konusunda uzman antrenörler tarafindan siklikla kullanılmaktadır (Fernandez ve ark., 2017; Palao ve Hernández-Hernández, 2014). Analiz programları branşa özgü olarak geliştirildiği için çok sayıda veriye doğru bir şekilde ulaşma imkanı sağlaması nedeniyle antrenörler tarafindan kullanışlı olarak nitelendirilmektedir. Analiz programlarından elde edilen verilerin doğru bir şekilde analiz edilmesi, antrenörlere antrenman planlaması ve takım taktiğinin belirlenmesi gibi konularda yardımcı olmaktadır (Baacke, 2005; Palao ve Hernandez-Hernandez, 2014; Fernandez-Echeverria ve ark., 2017; Joao ve ark., 2019).

Müsabakaların analiz edilmesinde kullanılan yöntemlerden birisi de yeni kullanılmaya başlayan YSA modelidir (Aka, 2020; Ayyıldız, 2018). Spor alanında kullanılan YSA biyolojiden esinlenerek geliştirilmiş bir algoritmadır (Bartlett, 2006). YSA, tahmin amacıyla girdi değerlerini alarak çıktı değerlerini kullanmaktadır. Geliştirilen YSA modeli ile sınıflandırma, veri ilişkilendirme, veri yorumlama ve veri filtreleme gibi işlemler yapılabilmektedir (Akkaya ve ark., 2009). YSA'nın 
Akarçeşme, C., Aka, H., Özden, S., \& Aktuğ, Z. B. (2020). Yapay sinir ağları ve doğrusal model ile 2016 Rio Olimpiyatlarındaki voleybol takım sıralamasının tahmin edilmesi. Journal of Human Sciences, 17(4), 1069-1078. doi:10.14687/jhs.v17i4.6077

eğitilmesi ve hedef sonuçlara ulaşılabilmesi için yoğun olarak girdi ve bu girdilere karşın çıkt dizilerine gereksinim duyulmaktadır. YSA insan beyninin niteliklerine göre; analizde bulunma, genelleme yapma, ilişkilendirmede bulunma, optimizasyon, öğrenme ve sınıflandırma gibi konularda başarılı bir biçimde uygulanabilmektedir (Öztemel, 2003). YSA probleme özel basit yapıları öğrenebilme, hatayı tolere edebilme ve modellenmesi güç olan, doğrusal olmayan karmaşık problemlere kolay çözümler sunabilme gibi üstünlüklerinden dolayı karmaşı sistemlerin modellenmesinde ve denetiminde çok geniş uygulama alanı bulmuştur. (Sağıroğlu ve ark., 2003).

Voleybolda klasik analiz yöntemleri kullanılarak yapılan maç analizlerinde, analiz uzmanının deneyimine ve yorumlarına ihtiyaç duyulması, doğru sonuçlara ulaşılmasını sınırlandıncı bir durum olabilir. Buna karşın geliştirilen YSA modeli ile yapilan analizlerde kişisel yorumlar yerine istatistiksel verilerden yararlanılarak sinir ağlarının yapacağı çıkarımlar ile daha nesnel sonuçlar elde edilmesi sağlanabilir. Literatürde YSA modeli kullanılarak voleybolun değerlendirildiği çalışmalar oldukça sinırlıdır (Tümer ve Koçer 2017; Kautz ve ark., 2017; Jörg ve ark., 2017; Koch ve Tilp, 2009). Uluslararası turnuvalardaki voleybol maç istatistiklerinin YSA modeli ile analiz edilmesine yönelik bir çalışma ise bulunmamaktadır. Bu bağlamda çalışmamız, 2016 Rio Olimpiyatlarına voleybol branşından katılma hakkı kazanan ülkelerin eleme gruplarındaki maçlarının, geliştirilen YSA ve Doğrusal Eşitlik Modeli ile analiz edilerek olimpiyat sıralamasının tahmin edilmesi amacı ile yapılmıştur.

\section{Materyal ve Metot}

Bu çalışmada, 2016 Rio Olimpiyatlarına voleybol branşından katılan (11 kadın ve 11 erkek voleybol takımı) toplam 22 takımın grup elemelerinde oynadığı tüm maçlar ( $\mathrm{n}=324)$ zorluk derecesi ve FIVB sıralama puanı göz önüne alınarak ayrı ayrı değerlendirilmiştir. Çalışmada takımların grup elemelerinde yaptığı maçların yanında, eleme grubundaki diğer takımların da matematiksel verileri kullanılmış; erkekler ve kadınlar için ayrı ayrı modellemeler yapılarak aynı giriş değişkenleri kullanılmıştır. Çalışmada kullanılan veriler için FIVB resmi internet sitesinden gerekli izin alınmıştır.

\subsection{Müsabakaların Zorluk Derecesinin Puanlaması}

Müsabakaların zorluk derecesi, FIVB tarafindan hazırlanan yıllık değerlendirme raporunda, maçların analizinde kullandığı ölçütler göz önüne alınarak hesaplanmıştır (FIVB Picture of the game, 2019). Hesaplama yöntemi aşağıdaki şekildedir.

Set skoru;

- 2 puan farkı ile sonuçlandiysa -20 puan

- 3-5 puan farkı ile sonuçlandiysa -15 puan

- 6-10 puan farkı ile sonuçlandiysa -10 puan

- 10 veya fazlası puan farkı ile sonuçlandiysa 0 puan

Yukarıdaki ölçütlere ek olarak;

- Eğer bir takım 25 puanın (son set ise 15) üzerine çıktıysa ekstra 5 puan

- Eğer her iki takımda 25 puanın (son set ise 15) üzerine çıktıysa ekstra 10 puan eklenmiştir. (FIVB Picture of the game, 2019). Elde edilen değerler tablo 1 ve tablo 2'de sunulmuştur.

FIVB puanı: FIVB'nin ülkelerin başarı sıralamasına göre belirlediği puanlardır (https://www.fivb.com/en/volleyball/rankings).

\subsection{Modellemede Kullanılan Giriş Parametreleri}

Parametre 1: Takımın olimpiyata gelmeye hak kazandığı eleme grubunda, takımın yaptığı maçların zorluk derecesi ortalaması

Parametre 2: Takımın olimpiyata gelmeye hak kazandığı eleme grubundaki tüm takımların yaptığı maçların zorluk derecesi ortalaması,

Parametre 3: Takımın olimpiyata gelmeye hak kazandığı eleme grubundaki tüm takımların yaptığı maçlardaki en yüksek zorluk derecesi, 
Akarçeșme, C., Aka, H., Özden, S., \& Aktuğ, Z. B. (2020). Yapay sinir ağları ve doğrusal model ile 2016 Rio Olimpiyatlarındaki voleybol takım sıralamasının tahmin edilmesi. Journal of Human Sciences, 17(4), 1069-1078. doi:10.14687/ihs.v17i4.6077

Parametre 4: Takımın olimpiyata gelmeye hak kazandığı eleme grubundaki tüm takımların yaptığı maçlardaki en düşük zorluk derecesi,

Parametre 5: Takımların FIVB puanı,

Parametre 6: Takımın FIVB puan değerindeki değişim,

Parametre 7: Takımın olimpiyata gelmeye hak kazandığı eleme grubundaki tüm takımların FIVB puan ortalamas1,

Parametre 8: Takımın olimpiyata gelmeye hak kazandığı eleme grubundaki en yüksek FIVB puan değeri,

Parametre 9: Takımın olimpiyata gelmeye hak kazandığ1 eleme grubundaki en düşük FIVB puan değeri.

\subsection{Modelleme}

Modellemede kullanılan giriş değişkenleri yukarıda bahsedilmiştir. Çıkış değişkeni takımların aldığı sıralama değeridir. Sıralama değerini matematiksel ifadeye dönüştürmek için her takıma sıralamasına göre puan verilmiştir. Olimpiyatlarda voleybol branşında toplam 12 takım bulunmaktadır. FIVB kurallarına göre, ev sahibi takım eleme maçları yapmadan olimpiyata doğrudan katılmaktadır. Bu sebeple modellemede ev sahibi takım çıartılmıştır. Ev sahibi takım hariç sıralamadaki en iyi takım 110 puandan başlamış, sıralamaya göre her bir sıra aşağıya inildikçe 10 puan azaltılmıştır. Böylece sonuncu olan takım 10 puan almıştır.

Tablo 1. Erkekler olimpiyat maç verileri

\begin{tabular}{|c|c|c|c|c|c|c|c|c|c|c|}
\hline & $\begin{array}{c}\text { Parametre } \\
1\end{array}$ & $\begin{array}{c}\text { Parametre } \\
2\end{array}$ & $\begin{array}{c}\text { Parametre } \\
3 \\
\end{array}$ & $\begin{array}{c}\text { Parametre } \\
4\end{array}$ & $\begin{array}{c}\text { Parametre } \\
5\end{array}$ & $\begin{array}{c}\text { Parametre } \\
6\end{array}$ & $\begin{array}{c}\text { Parametre } \\
7\end{array}$ & $\begin{array}{c}\text { Parametre } \\
8 \\
\end{array}$ & $\begin{array}{c}\text { Parametre } \\
9\end{array}$ & \\
\hline $\begin{array}{l}\text { Takım } \\
\text { Adı }\end{array}$ & $\begin{array}{c}\text { Takımların } \\
\text { grup maçı } \\
\text { zorluk } \\
\text { derecesi }\end{array}$ & $\begin{array}{c}\text { Grup } \\
\text { maçlarındaki } \\
\text { zorluk } \\
\text { derecesi }\end{array}$ & $\begin{array}{c}\text { Grup } \\
\text { maçlarındaki } \\
\text { maksimum } \\
\text { zorluk } \\
\text { derecesi }\end{array}$ & $\begin{array}{c}\text { Grup } \\
\text { maçlarındaki } \\
\text { minimum } \\
\text { zorluk } \\
\text { derecesi }\end{array}$ & $\begin{array}{c}\text { Takımın } \\
\text { Siralama } \\
\text { Puanı }\end{array}$ & $\begin{array}{l}\text { Takımın } \\
\text { Sıralama } \\
\text { Puanındaki } \\
\text { Değişimi }\end{array}$ & $\begin{array}{c}\text { Gruptaki } \\
\text { Takımların } \\
\text { Siralama } \\
\text { Puan Ort. }\end{array}$ & $\begin{array}{c}\text { Gruptaki } \\
\text { Takımların } \\
\text { Maksimum } \\
\text { Sıralama } \\
\text { Puanı }\end{array}$ & $\begin{array}{c}\text { Gruptaki } \\
\text { Takımların } \\
\text { Minimum } \\
\text { Sıralama } \\
\text { Puanı }\end{array}$ & Çık1ş \\
\hline İtalya & 49,55 & 54,17 & 105 & 30 & 256 & 0 & 149,58 & 268 & 36 & 110 \\
\hline ABD & 44,09 & 54,17 & 105 & 30 & 268 & 3 & 149,58 & 268 & 36 & 100 \\
\hline Rusya & 48,00 & 57,50 & 95 & 30 & 236 & -2 & 127,75 & 268 & 61 & 90 \\
\hline Arjantin & 33,33 & 59,17 & 100 & 10 & 168 & 0 & 58,75 & 168 & 12 & 80 \\
\hline Kanada & 66,43 & 59,46 & 95 & 30 & 152 & 4 & 118,63 & 268 & 43 & 70 \\
\hline İran & 67,86 & 59,46 & 95 & 30 & 163 & 3 & 118,63 & 268 & 43 & 60 \\
\hline Polonya & 57,86 & 59,46 & 95 & 30 & 268 & 0 & 118,63 & 268 & 43 & 50 \\
\hline Misir & 51,25 & 48,21 & 85 & 20 & 74 & 8 & 23,86 & 74 & 0 & 40 \\
\hline Fransa & 52,14 & 59,46 & 95 & 30 & 142 & 2 & 118,63 & 268 & 43 & 30 \\
\hline Küba & 48,33 & 54,17 & 95 & 40 & 72 & 4 & 76,50 & 152 & 29 & 20 \\
\hline Meksika & 66,67 & 60,00 & 100 & 40 & 53 & 7 & 28,25 & 53 & 12 & 10 \\
\hline
\end{tabular}

Tablo 2. Kadınlar olimpiyat mac verileri

\begin{tabular}{|c|c|c|c|c|c|c|c|c|c|c|}
\hline & $\begin{array}{c}\text { Parametre } \\
1\end{array}$ & $\begin{array}{c}\text { Parametre } \\
2\end{array}$ & $\begin{array}{c}\text { Parametre } \\
3\end{array}$ & $\begin{array}{c}\text { Parametre } \\
4\end{array}$ & $\begin{array}{c}\text { Parametre } \\
5\end{array}$ & $\begin{array}{c}\text { Parametre } \\
6\end{array}$ & $\begin{array}{c}\text { Parametre } \\
7 \\
\end{array}$ & $\begin{array}{c}\text { Parametre } \\
8 \\
\end{array}$ & $\begin{array}{c}\text { Parametre } \\
9 \\
\end{array}$ & \\
\hline Takım Adı & $\begin{array}{c}\text { Takımların } \\
\text { grup maçı } \\
\text { zorluk } \\
\text { derecesi }\end{array}$ & $\begin{array}{c}\text { Grup } \\
\text { maçlarındaki } \\
\text { zorluk } \\
\text { derecesi }\end{array}$ & $\begin{array}{c}\text { Grup } \\
\text { maçlarındaki } \\
\text { maksimum } \\
\text { zorluk } \\
\text { derecesi }\end{array}$ & $\begin{array}{c}\text { Grup } \\
\text { maçlarındaki } \\
\text { minimum } \\
\text { zorluk } \\
\text { derecesi }\end{array}$ & $\begin{array}{c}\text { Takımın } \\
\text { Siralama } \\
\text { Puanı }\end{array}$ & $\begin{array}{l}\text { Takımın } \\
\text { Sıralama } \\
\text { Puanındaki } \\
\text { Değişimi }\end{array}$ & $\begin{array}{c}\text { Gruptaki } \\
\text { Takımların } \\
\text { Sıralama } \\
\text { Puan Ort. }\end{array}$ & $\begin{array}{c}\text { Gruptaki } \\
\text { Takımların } \\
\text { Maksimum } \\
\text { Sıralama } \\
\text { Puanı }\end{array}$ & $\begin{array}{l}\text { Gruptaki } \\
\text { Takımların } \\
\text { Minimum } \\
\text { Sıralama } \\
\text { Puanı }\end{array}$ & Ç1k1ş \\
\hline Çin & 41,50 & 34,92 & 115 & 0 & 328 & 2 & 142,33 & 328 & 18 & 110 \\
\hline Sirbistan & 30,45 & 34,92 & 115 & 0 & 262 & 3 & 142,33 & 328 & 18 & 100 \\
\hline ABD & 34,00 & 38,64 & 70 & 0 & 305 & -1 & 77,50 & 305 & 14 & 90 \\
\hline Hollanda & 38,57 & 48,57 & 95 & 10 & 148 & 4 & 100,13 & 178 & 24 & 80 \\
\hline Japonya & 57,86 & 48,57 & 95 & 10 & 178 & -1 & 100,13 & 178 & 24 & 70 \\
\hline Kore & 56,43 & 48,57 & 95 & 10 & 100 & -1 & 100,13 & 178 & 24 & 60 \\
\hline Rusya & 45,00 & 51,25 & 90 & 15 & 218 & -1 & 98,63 & 218 & 37 & 50 \\
\hline Arjantin & 32,50 & 36,00 & 60 & 0 & 100 & 2 & 29,20 & 100 & 1 & 40 \\
\hline İtalya & 49,29 & 48,57 & 95 & 10 & 130 & 0 & 100,13 & 178 & 24 & 30 \\
\hline Kamerun & 60,00 & 49,64 & 95 & 15 & 45 & 9 & 21,29 & 45 & 9 & 20 \\
\hline Porto Riko & 25,00 & 22,50 & 45 & 0 & 67 & 2 & 33,25 & 67 & 18 & 10 \\
\hline
\end{tabular}


Akarçeșme, C., Aka, H., Özden, S., \& Aktuğ, Z. B. (2020). Yapay sinir ağları ve doğrusal model ile 2016 Rio Olimpiyatlarındaki voleybol takım sıralamasının tahmin edilmesi. Journal of Human Sciences, 17(4), 1069-1078. doi:10.14687/ihs.v17i4.6077

Modellemelerde veriler rastgele olacak şekilde ayrilmamıştır. Bu durumun sebebi, YSA ile doğrusal modellemenin birbiri ile kolaylıkla karşılaştırılmasıdır. Verinin çok fazla olduğu çalışmalarda rastgele olacak şekilde ayrılmasında bir sakınca yok iken, bu çalışmadaki gibi verinin az olmasi durumunda, veri setlerini belirlemek daha uygundur.

\subsection{Yapay Sinir Ağları Modeli}

YSA ile modellemede iki gizli katmana sahip ileri yayılımlı ağ yapısı tercih edilmiştir. Giriş parametreleri dokuz adet olup ilgili bölümde detaylı anlatılmıştır. Çıkış değişkeni takımın Olimpiyat sonunda kazandığı konumdur ve puanlama olarak belirlenmiştir. Çalışmada farklı ağ yapıları erkekler ve kadınlar için ayıı ayıı denenmiş olup, erkekler grubuna ait veriler için 9-10-5-1; kadınlar grubuna ait veriler için ise 9-20-8-1 ağ yapısı daha yüksek doğrulukla modelleme gerçekleştirmiştir. YSA'larının çalıştırılmasında geliştirilen kodlar MATLAB ortamında yazılmış ve grafikler elde edilmiştir.

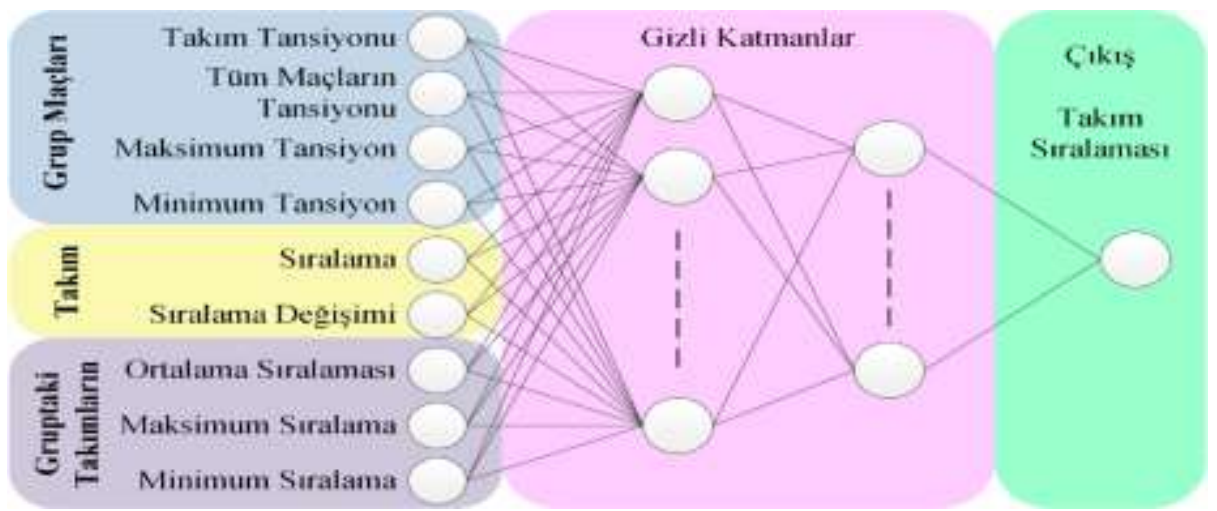

Şekil 1. Yapay sinir ağlarının giriş - çıkış değişkenleri ve ağ yapısı

Ev sahibi takım çıkartılınca geriye kalan 11 takımın verilerinden; 7 tanesi ağın eğitiminde, 2 tanesi doğrulamada ve 2 tanesi de testte kullanmak üzere ayrllmıştır.

\subsection{Doğrusal Modelleme}

Doğrusal modellemede kullanılan matematiksel ifade aşağıda sunulmuştur.

$$
T S=\beta_{0}+\beta_{1} \times P_{1}+\beta_{2} \times P_{2}+\ldots+\beta_{9} \times P_{9}
$$

Burada TS; takım siralamasını, $P_{n}$;modellemede kullanılan $\mathrm{n}$ th parametreyi, $\beta_{n}$; bu parametrenin katsayılarını, $\beta_{0}$;ise modelin sabit değerini göstermektedir. Modellemede parametrelerinin katsayılarının tahmin edilmesi amaçlanmıştır. YSA'na göre çok daha basit bir hesaplama sağlayan doğrusal modelleme, MATLAB'de bulunan "regress" komutu ile gerçekleştirilmiştir. Ev sahibi takım çıkartılınca geriye kalan 11 takımın verilerinden; 9 tanesi modellemenin matematiksel ifadesini oluşturmada, 2 tanesi de testte kullanılmak üzere ayrilmıştur.

\section{Bulgular}

2016 yılında Brezilya Rio'da gerçekleştirilen Olimpiyatlardaki voleybol takım sıralamasının tahmin edilmesi üzerine yapılan bu çalışmada, modellerden elde edilen sonuçlar her bir grup için ayrı ayrı sunulmuştur. Her bir grup için yapay sinir ağları ve doğrusal regresyon yöntemlerinden elde edilen modeller test verileri ile değerlendirilmiştir. Modellerin testinde, en yaygin olan ortalama mutlak hata $(\mathrm{OMH})$, ortalama mutlak yüzde hata $(\mathrm{OMYH})$, ortalama karesel hata $(\mathrm{OKH})$ ve $\mathrm{R}^{2}$ göstergelerinin sonuçları tablolar halinde sunulmuştur. 
Akarçeşme, C., Aka, H., Özden, S., \& Aktuğ, Z. B. (2020). Yapay sinir ağları ve doğrusal model ile 2016 Rio Olimpiyatlarındaki voleybol takım sıralamasının tahmin edilmesi. Journal of Human Sciences, 17(4), 1069-1078. doi:10.14687/jhs.v17i4.6077

Tablo 3. Kadınlar grubunun doğrusal modelleme istatiksel analiz sonuçları

\begin{tabular}{ccccc}
\hline & OMH & OMYH & OKY & $\mathbf{R}^{\mathbf{2}}$ \\
\hline Eğitim (Training) & 3,78 & 6,50 & 6,37 & 0,98 \\
\hline Test & 4,16 & 4,53 & 5,88 & 1,00 \\
\hline
\end{tabular}

OMH: Ortalama mutlak hata OMYH: Ortalama mutlak yüzde hata OKH: Ortalama karesel hata
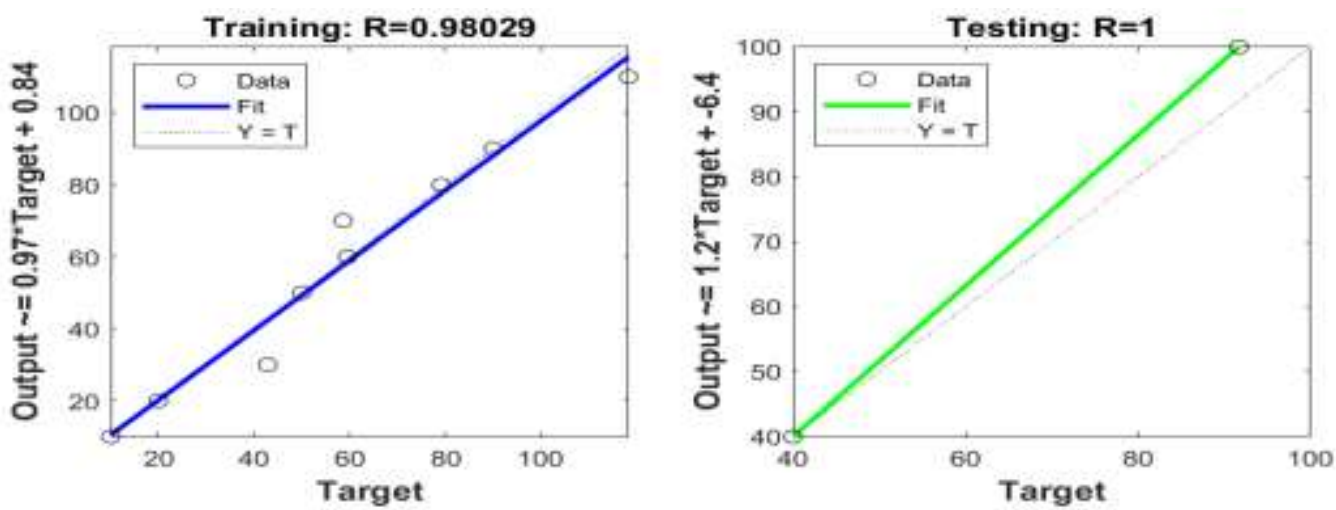

Şekil 2. Kadınlar grubunun doğrusal modelleme regresyon sonuçları

Tablo 4. Kadınlar grubunun yapay sinir ağları modelleme istatiksel analiz sonuçları

\begin{tabular}{ccccc}
\hline & OMH & OMYH & OKY & $\mathbf{R}^{\mathbf{2}}$ \\
\hline Eğitim (Training) & 4,76 & 9,82 & 6,45 & 0,99 \\
\hline Doğrulama (Validation) & 21,08 & 21,08 & 26,61 & 1,00 \\
\hline Test & 7,53 & 18,86 & 7,89 & 1,00 \\
\hline OMH: Ortalama mutlak hata OMYH: Ortalama mutlak vüzde hata OKH: Ortalama karesel hata
\end{tabular}
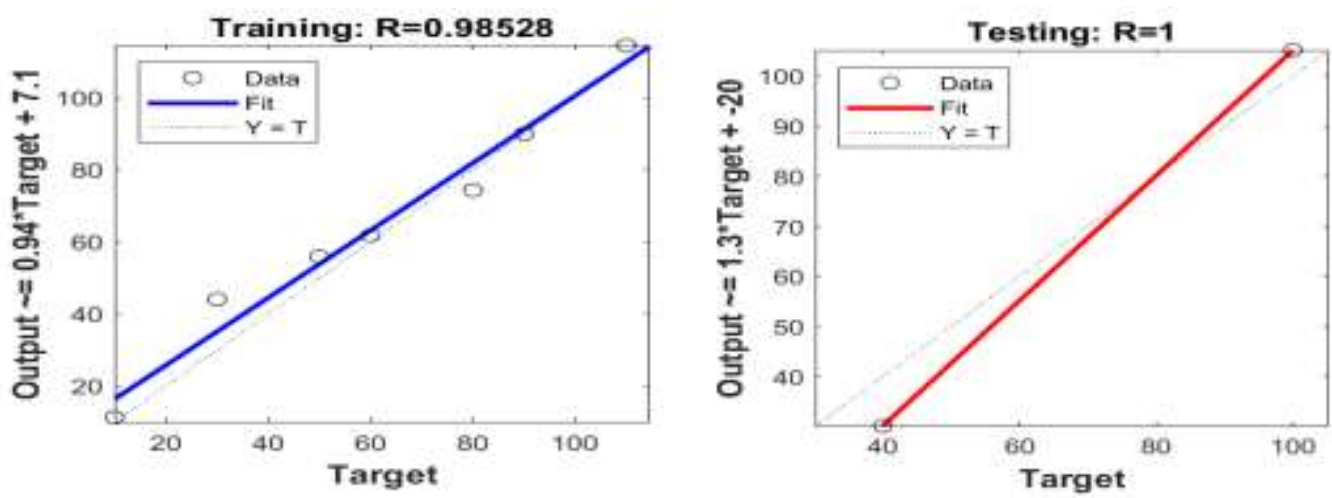

Şekil 3. Kadınlar grubunun yapay sinir ağları modelleme regresyon sonuçları

Kadınlar grubundaki modelleme sonuçlarına göre; korelasyon katsayısı $\left(\mathrm{R}^{2}\right)$ açısından bakıldığında her iki modelde yüksek doğruluğa $(>0.98)$ sahip sonuçlar üretmiştir. Bunun yanında gerçek hata değerlerine bakıldığında eğitim sonuçları birbirine yakın çıkmasına karşılık, test sonuçları doğrusal modelleme daha düşük hata ile sonuca ulaşmıştır.

Tablo 5. Erkekler grubunun doğrusal modelleme istatiksel analiz sonuçları

\begin{tabular}{ccccc}
\hline & OMH & OMYH & OKY & $\mathbf{R}^{\mathbf{2}}$ \\
\hline Eğitim (Training) & 1,70 & 2,65 & 3,03 & 1,00 \\
\hline Test & 0,75 & 0,74 & 1,07 & 1,00 \\
\hline
\end{tabular}

OMH: Ortalama mutlak hata OMYH: Ortalama mutlak yüzde hata OKH: Ortalama karesel hata 
Akarçeșme, C., Aka, H., Özden, S., \& Aktuğ, Z. B. (2020). Yapay sinir ağları ve doğrusal model ile 2016 Rio Olimpiyatlarındaki voleybol takım sıralamasının tahmin edilmesi. Journal of Human Sciences, 17(4), 1069-1078. doi:10.14687/jhs.v17i4.6077
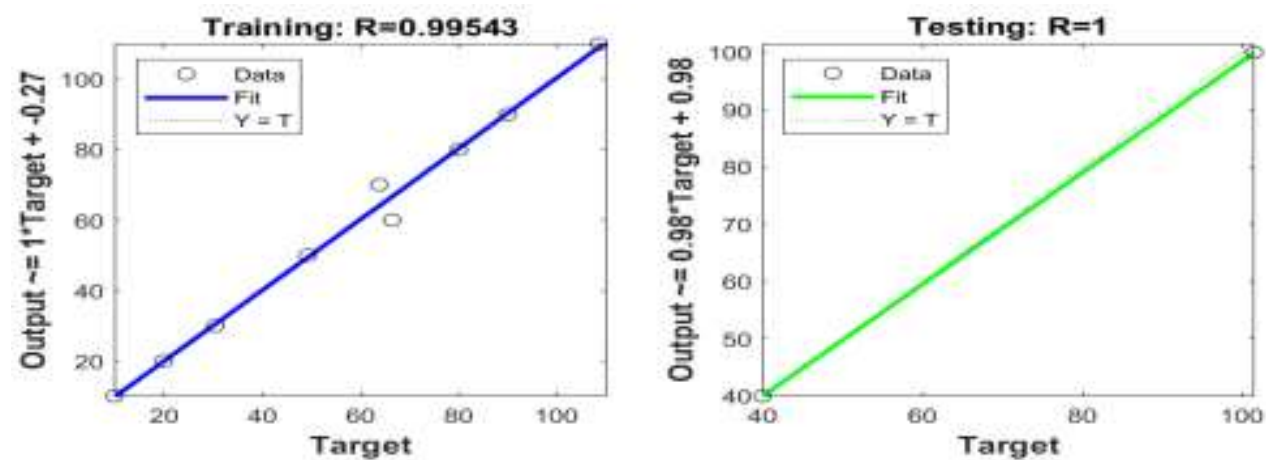

Şekil 4. Erkekler grubunun doğrusal modelleme regresyon sonuçları

Tablo 6. Erkekler grubunun yapay sinir ağları modelleme istatiksel analiz sonuçları

\begin{tabular}{ccccc}
\hline & OMH & OMYH & OKY & $\mathbf{R}^{2}$ \\
\hline Eğitim (Training) & 4,31 & 11,85 & 6,01 & 0,98 \\
\hline Doğrulama (Validation) & 11,89 & 11,89 & 14,97 & 1,00 \\
\hline Test & 10,65 & 19,34 & 10,84 & 1,00 \\
\hline
\end{tabular}

OMH: Ortalama mutlak hata OMYH: Ortalama mutlak yüzde hata OKH: Ortalama karesel hata
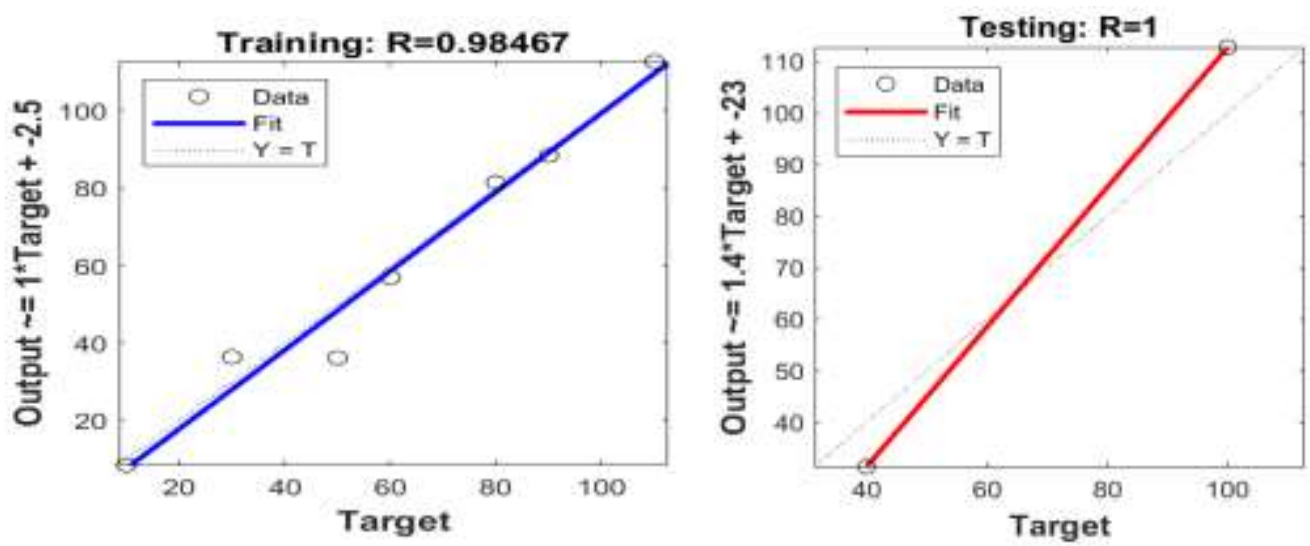

Şekil 5. Erkekler grubunun yapay sinir ağları modelleme regresyon sonuçları

Erkekler grubundaki modelleme sonuçlarına göre; her iki model de yüksek doğruluğa $(>0.98)$ sahip sonuçlar üretmiştir. Bunun yanında gerçek hata değerlerine bakıldığında eğitim sonuçları birbirine yakın çıkmasına karşılık, test sonuçları doğrusal modellemede daha düşük hata ile sonuca ulaşmıstur.

\section{Tartışma}

Bu çalışmada 2016 Rio Olimpiyatlarında hem kadın hem de erkek voleybol takımlarının Olimpiyat sıralamasının tahmini için YSA modeli ve doğrusal modelleme yöntemleri kullanılmıştır. Modellemenin eğitilmesi ve parametrelerin belirlenmesi için, Olimpiyat öncesi grup eleme maçları giriş değişkeni olarak belirlenmiştir. Modellerin hassasiyetini artırmak, daha düşük hata değeri ile sonuca ulaşmak için dokuz adet giriş parametresi belirlenmiştir. Bu parametreler; takımların geldikleri eleme gruplarında oynanan maçların zorluk derecesi ve takımların FIVB sıralama puanı olarak iki ana gruba ayrılabilir. Yapılan analizlere göre voleybolda kadın ve erkek kategorisinde Olimpiyatlara katılan takımların eleme grubundaki yaptığı maçların zorluk derecesi ve takımların FIVB sıralamasının, Olimpiyat oyunlarında voleybol branşının ülke sıralamasında belirleyici faktörler olduğu bulunmuştur. 
Akarçeșme, C., Aka, H., Özden, S., \& Aktuğ, Z. B. (2020). Yapay sinir ağları ve doğrusal model ile 2016 Rio Olimpiyatlarındaki voleybol takım sıralamasının tahmin edilmesi. Journal of Human Sciences, 17(4), 1069-1078. doi:10.14687/ihs.v17i4.6077

Kadınlar grubuna bakıldığında FIVB, olimpiyata katılacak ülkelerin belirlenmesi için yedi farklı eleme grubu oluşturmuştur. Olimpiyatlara katılan takımların iki tanesi dünya kupasından, iki takım NORCECA'dan, beş takım AVC'den ve birer takım CEV, SAVC ve AFRC'den katılmıştır. Takımların eleme gruplarında oynadığı toplam 162 maçın analizi gerçekleştirilmiştir. Takım ve grup temelli olmak üzere elde edilen veriler modellemelerin giriş parametrelerini oluşturmuştur.

Çalışmada elde edilen modelleme sonuçlarına göre; hem kadınlar hem de erkekler grubunun sonuçları doğrusal model ile daha yüksek doğrulukla modellenmiştir. Kadınlar grubunda; eğitim veri setindeki sonuçlar her iki model için de birbirine oldukça yakındır. Test verilerine bakıldığında gerçek ortalama hata değeri, YSA için 7.53 iken doğrusal model için 4.16 olmuştur. Bu hataya yüzdelik oranı açısından bakıldığında doğrusal ve YSA modelleri için sırası ile 4.53 ile 18.86 olduğu hesaplanmıştır. Doğrusal modelin ortalama gerçek yüzde hata değeri oldukça yakın bir sonuç üretmiştir. Modellerin regresyon sonucu, test verileri için 0.99 'dan daha büyük bir değer ürettiği, modellerin yüksek hassasiyet ile sonuca ulaştığı görülmüştür.

Olimpiyatlarda yer alan 11 erkek takımının eleme gruplarında oynadığı toplam 162 maçın analizi gerçekleştirilmiştir. Eleme grubunda; modellerin regresyon sonucu test verileri için 0.99'dan daha büyük bir değer ürettiği, modellerin yüksek hassasiyet ile sonuca ulaştı̆̆ görülmüştür. Ancak bunların yanında, diğer önemli göstergeler olan $\mathrm{OMH}$, OMYH VE OKH değerlerine bakıldığında doğrusal modelin çok daha düşük sonuçlar ile modelleme gerçekleştirdiği belirlenmiştir. Yüzde ortalama hata değeri YSA'da 19.34 iken, doğrusal model 0.74 olarak hesaplanmıştır ve doğrusal modelde büyük bir fark görülmüştür. Aynı durum OKH değerinde de ortaya çıkmış, yaklaşık 10 kat daha düşük bir hata değeri oluşmuştur.

Literatürde voleybol branşında maçların zorluk derecesi ve FIVB sıralama puanlarının YSA modeli ile analiz edilerek takım sıralamasının değerlendirildiği bir çalışma bulunamamıştır. Bu durum çalışma sonuçlarımızın karşılaştırılmasını sınırlandırmışır. Geliştirilen YSA modeli ile lig sıralamasının tahmin edilmesine yönelik sınırlı sayıda çalışma olduğu görülmektedir. Tümer ve Koçer (2017) tarafindan yapılan bir çalışmada geliştirilen YSA modeli ile Türkiye voleybol lig sıralaması, 66 müsabakada takımların maçı kendi sahasında kazanma-kaybetme ve rakip sahada kazanma-kaybetme giriş değişkenlerine göre \%98 doğruluk oranıyla tahmin edilmiştir. Aka (2020) tarafindan yapılan benzer bir çalışmada geliştirilen YSA modeli ile Almanya Futbol Ligi (Bundesliga) takımlarının attığı ve yediği goller, pas ve topa sahip olma giriş değişkenleri kullanılarak sezon sonu lig sıralaması \%97'nin üzerinde doğruluk oranı ile tahmin edilmiştir.

Yukarıda belirtilen çalışmalar geliştirilen YSA modeli ile lig sıralamasını tahmin etmeye yönelik olmasına rağmen, çalışmalarda kullanılan giriş değişkenlerinin tamamen farklı olması dikkat çekmektedir. Ayrıca çalışmamızın belirli dönemlerde toplanan milli takımları kapsaması yönüyle yukarıdaki çalışmalardan farklılık göstermektedir.

Sonuç olarak, 2016 Rio Olimpiyat Oyunlarında voleybol branşının takım sıralaması kadınlar kategorisinde, YSA modelleme regresyon sonuçları ve doğrusal modelleme regresyon sonuçları ayrı ayr1 98\%’in üstünde doğrulukla tahmin edilmiştir. Erkek voleybol maçlarında yapay sinir ağları modelleme regresyon sonuçları $98 \%$ 'in üstünde, doğrusal modelleme regresyon sonuçları ise 99\%'un üstünde doğrulukla tahmin edilmiştir. Voleybolda Olimpiyatlara katılan ülkelerin eleme gruplarında oynadıkları maçların zorluk derecesi ve FIVB sıralama puanlarının Olimpiyat sıralamasının belirlenmesinde önemli etkisi olduğu söylenebilir.

Giriş değişkeni olarak, teknik molalardaki vesetlerdeki maç skorları ile kazanılan ve kaybedilen set sayılarının kullanılması yapılacak yeni çalışmalar için önerilebilir. 
Akarçeșme, C., Aka, H., Özden, S., \& Aktuğ, Z. B. (2020). Yapay sinir ağları ve doğrusal model ile 2016 Rio Olimpiyatlarındaki voleybol takım sıralamasının tahmin edilmesi. Journal of Human Sciences, 17(4), 1069-1078. doi:10.14687/ihs.v17i4.6077

\section{Kaynaklar}

Aka, H. (2020). Yapay sinir ağlar modeli ile futbolda takım sıralamasını tahmin edilmesi. Spor Bilimleri Alanında Akademik Çalışmalar-2. Ankara: Gece Kitaplı̆̆1 Yayın Evi. 173-182.

Akkaya, G.C., Demireli, E., \& Yakut, Ü.H. (2009). İşletmelerde finansal başarısızlık tahminlemesi: Yapay sinir ağları modeli ile İMKB üzerine bir uygulama. Eskissehir Osmangazi Üniversitesi Sosyal Bilimler Dergisi, 10(2), 187-216.

Ayyıldız, E. (2018). Amerika Basketbol Ligi (NBA) maç sonuçlarının yapay sinir ağları ile tahmini. Gaz̧iantep Üniversitesi Spor Bilimleri Dergisi, 3(1), 40-53.

Baacke, H. (2005). Voleybol antrenman üst düzey takımlar için el kitabı 2. Çeviri: Pekünlü, E. 1. baskı. İstanbul: Çağrı Baskı.

Bartlett, R. (2006). Artificial intelligence in sports biomechanics: New dawn or false hope. Journal of Sports Science and Medicine, 5(4), 474-479.

Koch, C., \& Tilp, M. (2009). Analysis of beach volleyball action sequences of female top athletes. Journal of Human Sport \& Exercise, 4(3), 272-283.

Fernandez-Echeverria, C., Mesquita, I., González-Silva, J., Claver, F., \& Moreno, M.P. (2017). Match analysis within the coaching process: A critical tool to improve coach efficacy. International Journal of Performance Analysis in Sport, 17(1-2), 149-163.

FIVB Picture of the game. (2019). International Volleyball Federation picture of the game. https://www.fivb.com/-/media/2020/fivb-corporate/volleyball/rules-of-the-game/7-2019-_ pictureofthegamereport--final-version.pdf?la=en [Erişim tarihi: 23.04.2020]

Gabbett, T., \& Georgieff, B. (2004). Physiological characteristics of elite junior volleyball players over a competitive season. Strength Condition Coaching, 13(1), 2-7.

Gabbett, T., \& Georgieff, B. (2007). Physiological and anthropometric characteristics of junior national, state, and novice volleyball players. Journal of Strength and Conditioning Research, 21(3), 902-908.

João, P.V., Vaz, L., \& Mota, M.P. (2019). The statistics which qualified Portugal for the European Volleyball Championship 2019. CIDESD 2019 International Congress, University Institute of Maia, Portugal, 1-2 February 2019. 139.

Jörg, M., Perl, J.J., \& Schöllhorn, W. (2017). Analysis of players' configuration by means of artifical neural networks. International Journal of Performance Analysis in Sport, 7(3), 90-105.

Marques, M.C., Van den Tillaar, R., Gabbett, T.J., Reis, V.M., \& Gonzalez-Badillo, J.J. (2009). Physical fitness qualities of professional volleyball players: Determination of positional differences. Journal of Strength and Conditioning Research, 23(4), 1106-1111.

Öztemel, E. (2003). Yapay sinir ağlar. Türkiye: Papatya Yayınevi.

Palao, J., \& Hernández-Hernández, E. (2014). Game statistical system and criteria used by Spanish volleyball coaches. International Journal of Performance Analysis in Sport, 14(2), 564-573.

Sağıroğlu, Ş., Beşdok, E., \& Erler, M. (2003). Mühendislikte yapay zekea uygulamalar 1 / Yapay sinir ağlar. Kayseri: Ufuk Kitap Kırtasiye-Yayıncılık Tic. Ltd. Şti.

Kautz, T., Groh, B.H., Hannink, J., Jensen, U., Strubberg, H., \& Bjoern M. (2017). Eskofier activity recognition in beach volleyball using a deep convolutional neural network. Data Mining and Knowledge Discovery, 31, 1678-1705

Tümer, A.E., \& Koçer, S. (2017). Prediction of team league's rankings in volleyball by artificial neural network method. International Journal of Performance Analysis in Sport, 17(3), 202-211.

FIVB (2020). https://www.fivb.com/en/volleyball/rankings [Erişim tarihi: 23.09.2020].

\section{Extended English Summary}

It is necessary to benefit from different fields, including technology, in order to achieve versatile improvement in elite athletes. Trainers can analyze the performances of athletes and teams easily thanks to the widespread use of computer technologies in recent years. ANN used in the sports field is an algorithm developed by inspiring biology (Bartlett, 2006). Artificial Neural Network gets input values and uses output values for estimation. Procedures such as classification, data association, data interpretation and filtration can be performed with the developed ANN model (Akkaya et al., 2009). The objective of this study is to estimate the Olympic rank by analyzing the games played in qualifying groups by the countries qualified for the 2016 Rio Olympics in volleyball branch via Artificial Neural Network and Linear Equality Model. In the study, the difficulty level of all games $(n=324)$ that total 22 
Akarçeșme, C., Aka, H., Özden, S., \& Aktuğ, Z. B. (2020). Yapay sinir ağları ve doğrusal model ile 2016 Rio Olimpiyatlarındaki voleybol takım sıralamasının tahmin edilmesi. Journal of Human Sciences, 17(4), 1069-1078. doi:10.14687/ihs.v17i4.6077

teams (11 female and 11 male volleyball teams) played in the qualifying for the 2016 Rio Olympics in volleyball branch and FIVB ranking score was evaluated separately.

The input parameters used in the modeling are as following;

Parameter 1: The average difficulty level of the games the team played in the qualifying group where it was qualified for the Olympics,

Parameter 2: The average difficulty level of the games of all teams in the qualifying group where the team was qualified for the Olympics,

Parameter 3: The highest difficulty level in the games of all teams in the qualifying group where the team was qualified for the Olympics,

Parameter 4: The lowest difficulty level in the games of all teams in the qualifying group where the team was qualified for the Olympics,

Parameter 5: FIVB scores of the teams,

Parameter 6: The change in the FIVB score value of the team,

Parameter 7: FIVB score average of all teams in the qualifying group where the team was qualified for the Olympics,

Parameter 8: The highest FIVB score value in the qualifying group where the team was qualified for the Olympics,

Parameter 9: The lowest FIVB score value in the qualifying group where the team was qualified for the Olympics.

Modeling

Home team was omitted in the modeling. The best team started with 110 points, and each rank decreased 10 points according to the ranking. Thus the last team got 10 points.

Artificial Neural Network Model

In the modeling with artificial neural network, feedforward network structure with two hidden layers was preferred. In the study, different network structures were tried for males and females separately, and 9-10-5-1 network structure for males and 9-20-8-1 network structure for females performed a modeling with a higher accuracy.

Linear Modeling

The mathematical expression used in the linear modeling is as following.

$$
T R=\beta_{0}+\beta_{1} \times P_{1}+\beta_{2} \times P_{2}+\ldots+\beta_{9} \times P_{9}
$$

TR indicates 'team ranking', $P_{n}$ indicates $\mathrm{n}$ th parameter used in the modeling, $\beta_{n}$ indicates the coefficients of this parameter, and $\beta_{0}$ indicates the fixed value of the model.

According to the modeling results in the women's group, both model produced results with high accuracy $(>0.98)$ in terms of correlation of coefficient $\left(\mathrm{R}^{2}\right)$

According to the modeling results in men's group, both model produced results with high accuracy $(>0.98)$.

In this study, in order to train the modeling and determine the parameters, qualifying games before the Olympics were determined as the input variable. Nine input parameters were specified to increase the sensitivity of the models and to have results with lower error value. These parameters can be divided into two main groups as the difficulty levels of the games played in the qualifying groups that the teams played in and the FIVB ranking scores of the teams. According to the analysis, it was found that the difficulty level of the games played in the qualifying by the teams participating in the Olympics in women and men's group in volleyball and the FIVB ranking of the teams are the determining factors in the country ranking in volleyball branch in the Olympic Games.

As a result, team rankings of the volleyball branch in the women's group in the 2016 Rio Olympic Games was estimated with an accuracy over 98\% separately by artificial neural network modeling regression results and linear modeling regression results. In men's volleyball games, it was estimated with accuracy over $98 \%$ by artificial neural network modeling regression results and with accuracy over $99 \%$ by linear modeling regression results. It can be stated that the difficulty level of the games played in the qualifying groups by the countries participating in Olympics in volleyball branch and FIVB ranking scores are among the variables that have a significant effect on determining the Olympic ranking. 